\title{
Mine water: management post-closure and lessons learned, risks from poor closure and mine water management
}

L.M. Wyatt The Coal Authority, UK

A.M.L. Moorhouse The Coal Authority, UK

S. Kershaw The Coal Authority, UK

B. Iwanskyj The Coal Authority, UK

\begin{abstract}
Following the reprivatisation of the coal industry in the UK in 1994, the Coal Authority was formed to manage the legacy and liabilities of former nationalised coal mining on behalf of the UK government. Part of this post-mining legacy includes the pollution from the contaminated water in the mine workings. Since 1994, the Coal Authority has constructed and operated over 60 mine water remediation schemes and has implemented an evolving network of nearly 2,000 monitoring points throughout the UK. Due to the organisation's knowledge and expertise in managing mine water and developing treatment schemes, the Coal Authority was granted permission to investigate the remediation of non-coal-related mine water pollution. Over the previous 19 years of managing coal mine water on both a local and regional scale, the Authority has gained a significant amount of knowledge and experience, highlighting a number of important examples of 'lessons learned' for future closing mine sites. This paper is designed to highlight some key factors and methods in understanding, developing and managing mine water pollution postclosure and other mining-associated risks.

Part of the historical mining legacy in the UK is the significant problems and potential risks with regard to managing coalfields post-closure. Such issues range from lack of appropriate monitoring sites due to shaft filling, poor maintenance of old mine water drainage adits, blockages or failure of obstructions (e.g., dams) in underground workings and the risks of mine gases due to rising mine water. In addition to these issues, the Coal Authority has continually developed its systems to better manage mine waters and make future predictions in an attempt to understand and mitigate the impact of environmental issues. This paper describes how changes have been made over time to a monitoring network, along with the parameters requiring monitoring. It also uses case studies to highlight problems of previous versus current strategies to prevent aquifer pollution, treat mine water and adapt to changes in environmental regulations over time.
\end{abstract}

\section{Introduction}

After the closure and abandonment of numerous mines and coalfields throughout the UK, with various areas ceasing production during the 1980s and 1990s, the pumping of water from the workings ceased, resulting in the flooding of the mines. Within the mining infrastructure of coalfields and individual mines, various factors influence how the workings fill with water and how the mine water rebounds. Such factors include the type of mine workings, the size and volume of the worked areas, any interconnections between mines and mining units, relationships to surrounding strata and connections to older workings and drainage systems. Each of these factors will have varying effects on how mine waters recover in terms of both the initiation and longevity of the rebound and any future associated risks this may represent.

The risks from mine water rebound are not limited to the environment in terms of surface water pollution, they also include the risks to potable water aquifers, risks to the public from mine gases, risks of rising mine water affecting groundwater levels, and risks due to sudden releases (blowouts) of mine water, typically from mine adits. This paper utilises past experience and knowledge from managing coalfield-wide water 
and risks and illustrates a series of case studies highlighting examples, demonstrating the mechanisms employed by the Coal Authority in order to successfully manage and understand the impacts of coalfield (and mine) abandonment with respect to water and water-related issues.

\section{Early years}

This section discusses the situation presented to the Coal Authority following re-privatisation of the coal industry in 1994, in addition to the measures undertaken during the 1990s to manage the coal mine water (and mine gas) present within the UK. The following sub-sections describe the number of monitoring and pumping sites inherited, the types of mine water treatment schemes and design parameters employed, the types of sites inherited by the organisation and the early monitoring network that was established, which subsequently highlighted significant gaps in data.

\subsection{Inherited monitoring and operational sites}

In addition to the estate and land interests inherited from British Coal, the Authority was also granted the responsibility of managing this estate and any liabilities (Coal Industry Act, 1994). These liabilities include claims for mining-related subsidence and other associated mining-related hazards, such as collapses of mine workings, mine water discharges and mine gas issues. At the time of the initial handover, there were only 82 monitoring sites located throughout a limited number of the major coalfields in the UK. Initially, these 82 sites were divided into 14 water pumping stations, 35 gas vents, 4 gravity discharges and 29 water monitoring sites (Wyatt et al., 2011); the majority of these sites utilised disused mine shafts and adits, although some gas vents were installed into old workings and some adits.

Figure 1, which shows these initial 82 sites in conjunction to the additional sites establish by the Authority up to about 2000, shows that there were initially several large gaps in both the monitoring and knowledge of the mine gas and water within various parts of the UK.

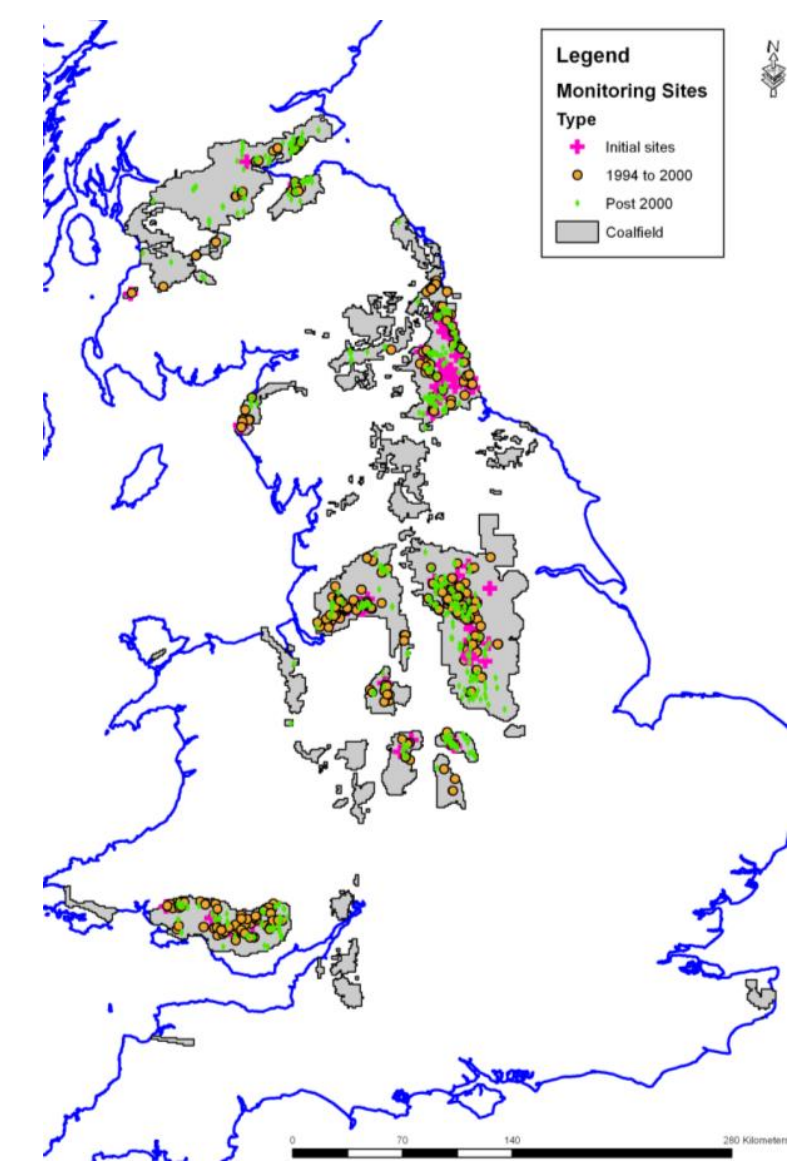

Figure 1 Map of the coalfields of the UK, showing monitoring point locations 
Consequently, there was a requirement for a rapid increase in the number of sites around the UK, which are shown on Figure 2. This increase in the number of sites enabled the development of an improved monitoring network, which enhanced the understanding of water regimes within defined mining blocks. The increase in monitoring locations coincided with the development of more-advanced monitoring parameters and data collection (Wyatt et al., 2011), obtaining improved flow measurements and chemistry data from gravity discharges and mine water treatment schemes and, more recently, obtaining on-site, real-time chemical data. All the data are used to improve the knowledge of how the mining systems work and to monitor the performance of the associated mine water treatment schemes.

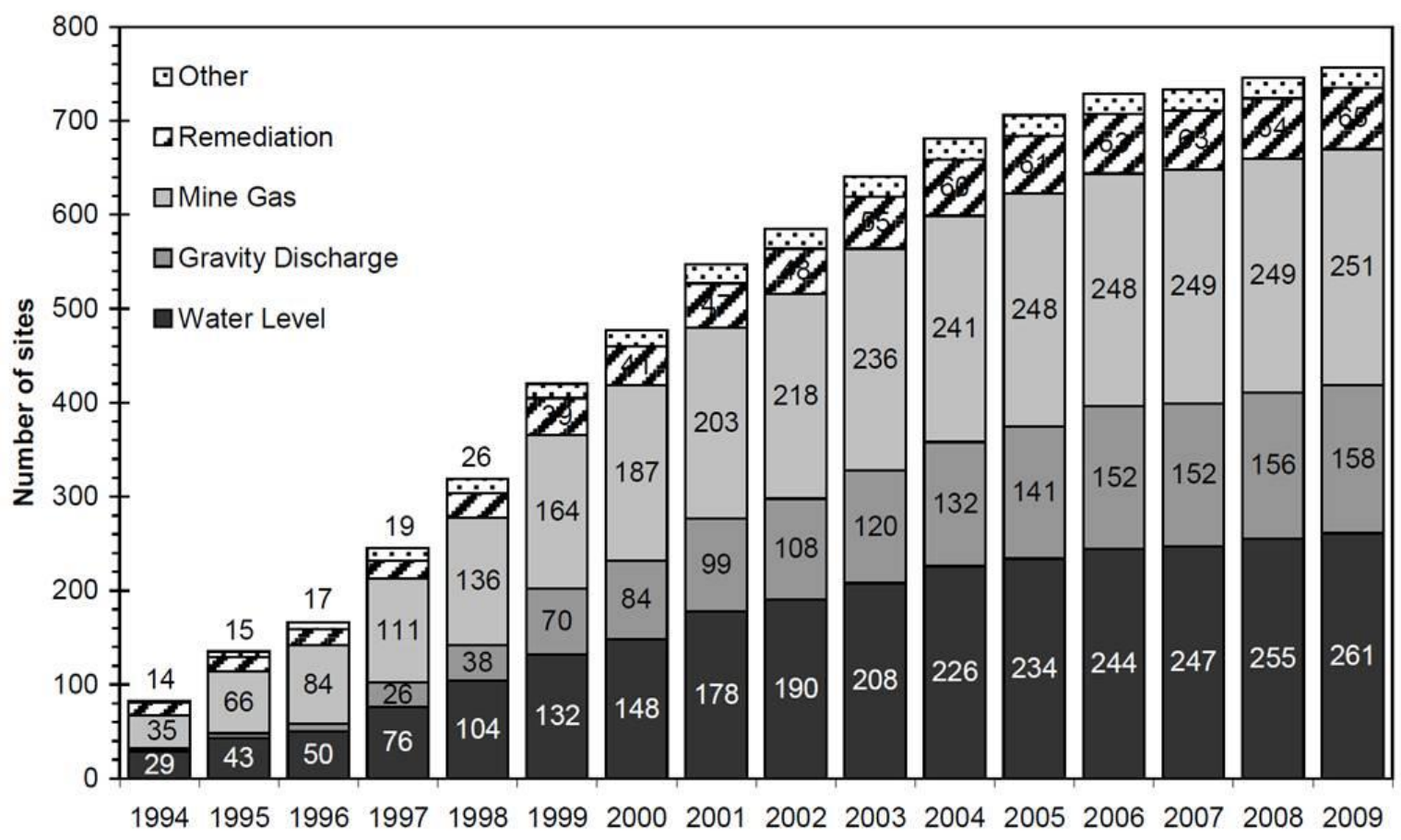

Figure 2 Number of monitoring sites over time (from Wyatt et al., 2011)

\section{$2.2 \quad$ Early mine water treatment}

Of the original inherited locations, a total of 14 were pumping sites and 3 were mine water treatment schemes. These treatment schemes are designed to remove iron from the mine water before discharging the water into a nearby watercourse. Initially, the design of the mine water treatment schemes was based on experience gained from a limited number of pre-existing sites; consequently, the early treatment schemes had either a descriptive consent, or a consent of typically $10 \mathrm{mg} / \mathrm{L}$ of iron. The current environmental quality standard in the UK is $1 \mathrm{mg} / \mathrm{L}$ of dissolved iron. With the high discharge consent limit of $10 \mathrm{mg} / \mathrm{L}$, many of the pumping stations discharged water directly into the adjacent watercourses (Figure 3).

The initial treatment methods for iron removal included the passive methodologies of settlement ponds and reed beds, as well as chemical dosing in certain instances. As the treatment programme expanded and a better understanding of processes was developed, there came a desire to improve effluent quality. This resulted in new and improved discharges consents being imposed by the regulatory bodies. Typically these tighter consents required the iron to be treated down to concentrations of either $2 \mathrm{mg} / \mathrm{L} \mathrm{or} 5 \mathrm{mg} / \mathrm{L}$ of iron. To achieve these concentrations, it was necessary for the Authority to improve its existing schemes. And looking forwards, further work was needed to ensure these stricter discharge values were met, or surpassed, in any future schemes. Therefore, in order to successfully treat mine water passively (or semipassively), some changes to scheme development were required; typically these responses were to make the schemes larger, allowing longer residence times for the iron to precipitate out of solution, the addition of aerobic wetlands (reed beds) and, in some cases, improvements to aeration cascades. 


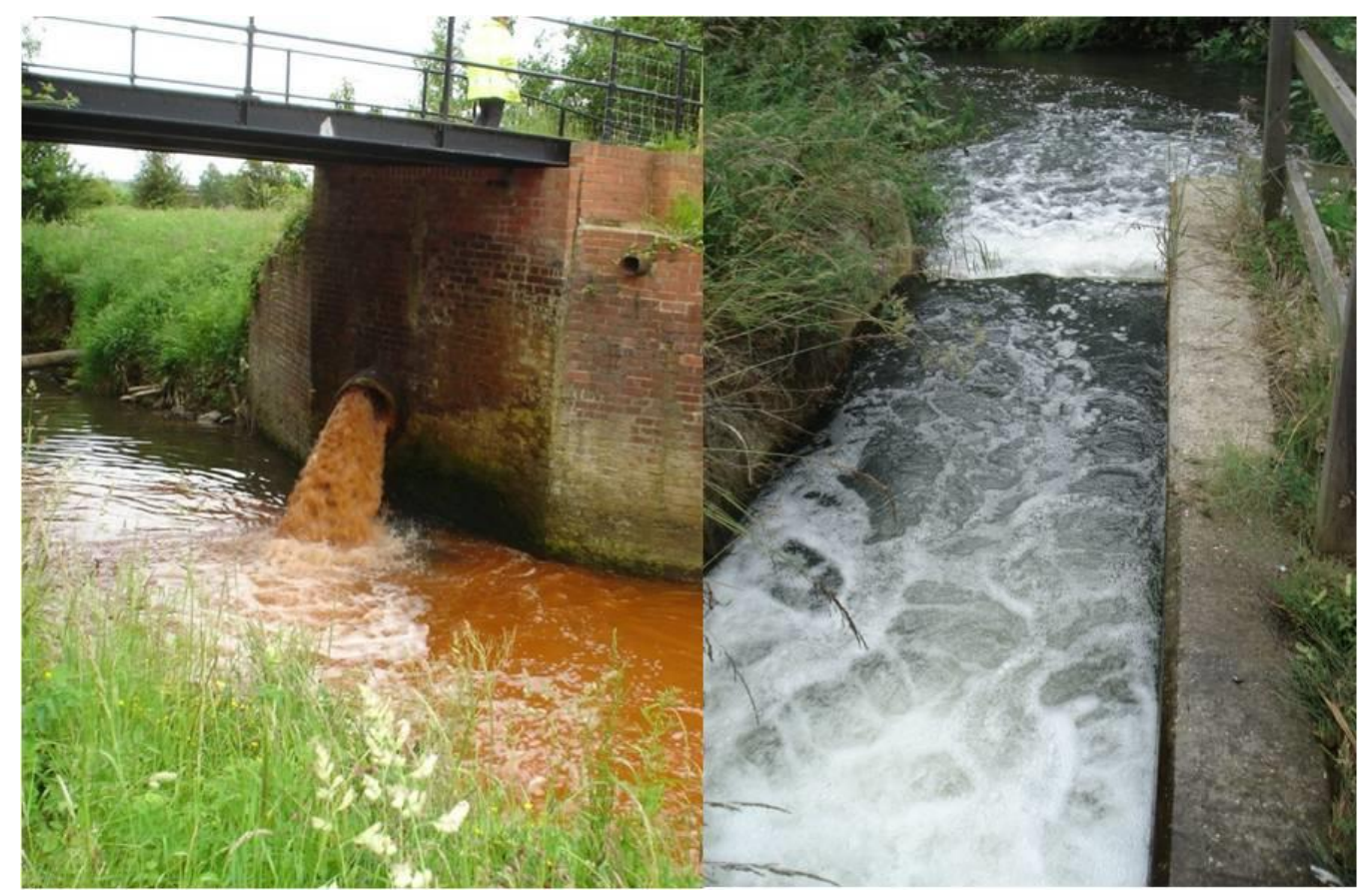

\section{Figure 3 Untreated pumped mine water from Kibblesworth, prior to the Lamesley co-treatment scheme (left (Coal Authority $\odot$ May 2005)) and the outlet from the co-treatment scheme (right (Coal Authority @ June 2009))}

\section{$3 \quad$ Predicting mine water rebound and mine water chemistry}

With the development of a mine water monitoring network and a database of mine water levels and chemistry, the next logical step was to attempt to predict and model the recovering mine water. This is to aid with:

- Determining the timing of mine water rebound and identifying potential outbreaks to the surface and contamination of aquifers.

- Determining the potential rest water level and identify any areas of risk.

- Attempting to predict any likely locations for mine water outbreaks.

Initial computerised modelling was developed to reflect the nature of the mining, and it included early models for the mine water recovery at locations such as Whittle and Blaenant (Cefn Coed) (Younger and Adams, 1999; Adams and Younger, 2001) for a collation of results from a number of differing methods. However, these models were based on a number of key assumptions, which include levels of connections, overflow levels, mine water barriers and potential discharge locations. The following sections describe two examples from different regions in the UK, demonstrating the use of these models and the practical application of using real data to extrapolate and predict the rebound of mine water in areas of recovery.

\subsection{Blaenant / Ynysarwed, South Wales}

The predictions for Blaenant Colliery (Adams and Younger, 2001) suggested that the mine water would recover to surface and emerge from the shaft at Cefn Coed; a pipe was therefore installed to facilitate this discharge of the mine water. In reality however, the water migrated through an approximate $70 \mathrm{~m}$ barrier of un-worked coal and sandstone strata, and emerged approximately $2.7 \mathrm{~km}$ to the southeast in a separate valley, causing pollution of the Neath Canal and River Neath. In response to this event, the water was treated by an active (chemical) and part passive scheme built by Neath Port Talbot Council. Subsequent to the scheme construction, and after some initial monitoring of mine water levels that later ceased at Cefn Coed due to safety concerns, it was assumed that all the water was migrating along this preferred flow path and was discharging to the scheme at Ynysarwed. 
More recently, however, the decision was taken to verify the mine water situation at both Cefn Coed and in some adjacent Environment Agency boreholes. Interpretation of the data by the Coal Authority indicated that not all of the water was being discharged at Ynysarwed and that mine water levels in the area were still rising (Figure 4). In 2012, the mine water at Cefn Coed reached the shaft overflow culvert and started to discharge mine water to the surface. Currently this mine water is low flow $(<5 \mathrm{~L} / \mathrm{s})$ combined with a relatively low iron concentration (c. $15-20 \mathrm{mg} / \mathrm{L}$, compared with c. $100 \mathrm{mg} / \mathrm{L}$ at Ynysarwed); the Coal Authority is currently monitoring this ongoing situation and assessing whether any additional works or treatment will be required.

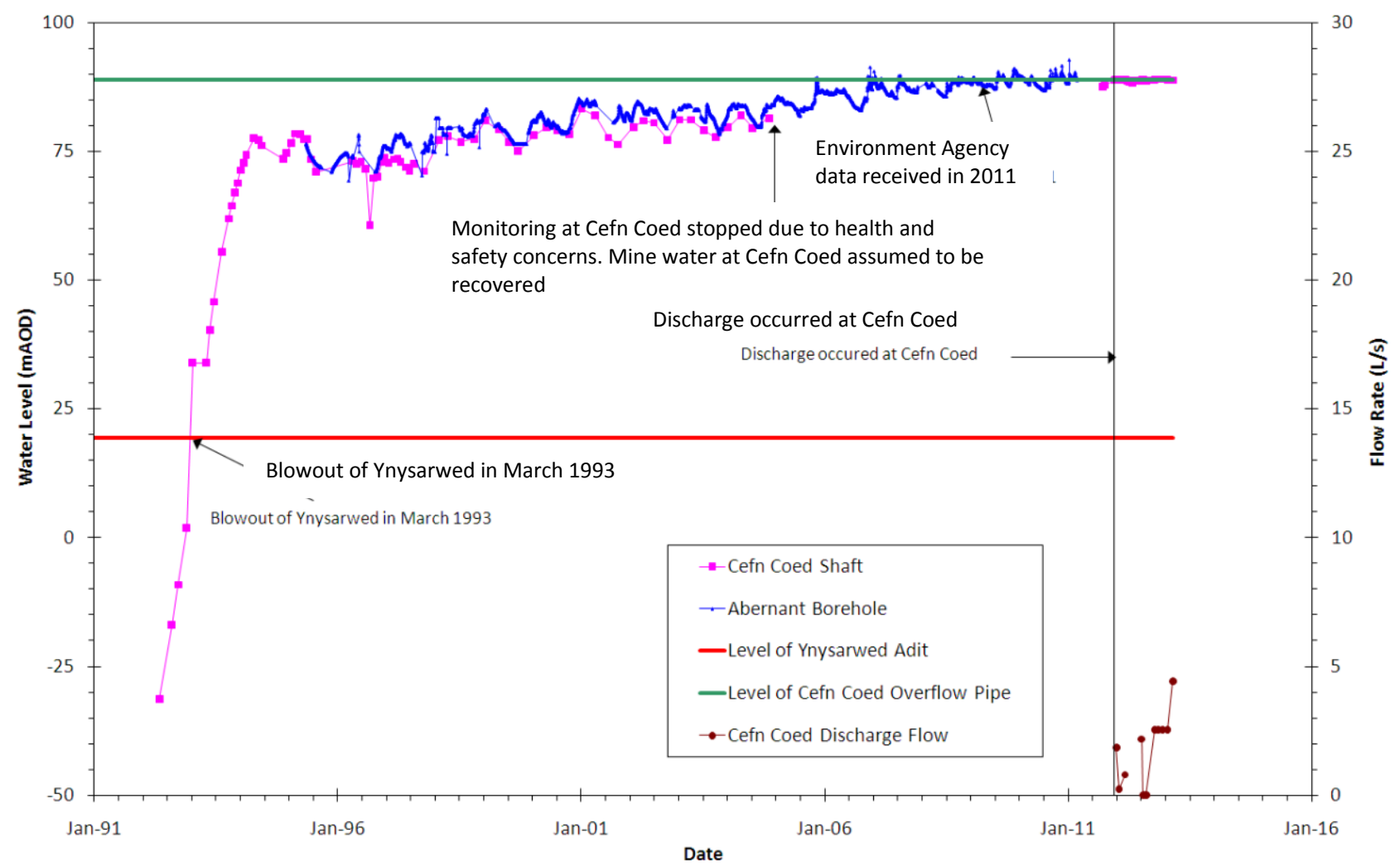

Figure 4 Blaenant (Cefn Coed) water levels, flow rates and Ynysarwed discharge level

\subsection{Monitoring and projection approach, Northeast England}

In some instances, especially where there are limited data available, numerical models work relatively effectively. However, a differing approach is to use recorded measurements of mine water levels in order to predict the rising mine water trend for a specific mine within a mining block. Figure 5 shows some typical mine water recovery patterns throughout the UK. Using such data, projections of the recovery curves (usually exponential) can be made to assess, reasonably accurately, the timing of when water levels will reach a certain level (i.e., discharge level).

Within the Northeast of England, the Horden and Bates mining blocks were both monitored during their periods of recovery. From the data, projections were made (Figure 6) and used to determine the timing of when mine water pumping (and treatment) would be required. This provided a sufficient notice period to allow for both the planning and construction of treatment systems that were successfully operational in sufficient time to prevent and mitigate the impacts of these rising mine waters. It should also be noted that both of these areas are influenced by 'tidal-pressure' responses (Whitworth, 2002a), thus data-loggers were also utilised to obtain an improved record of the data and to model the tidal responses. 


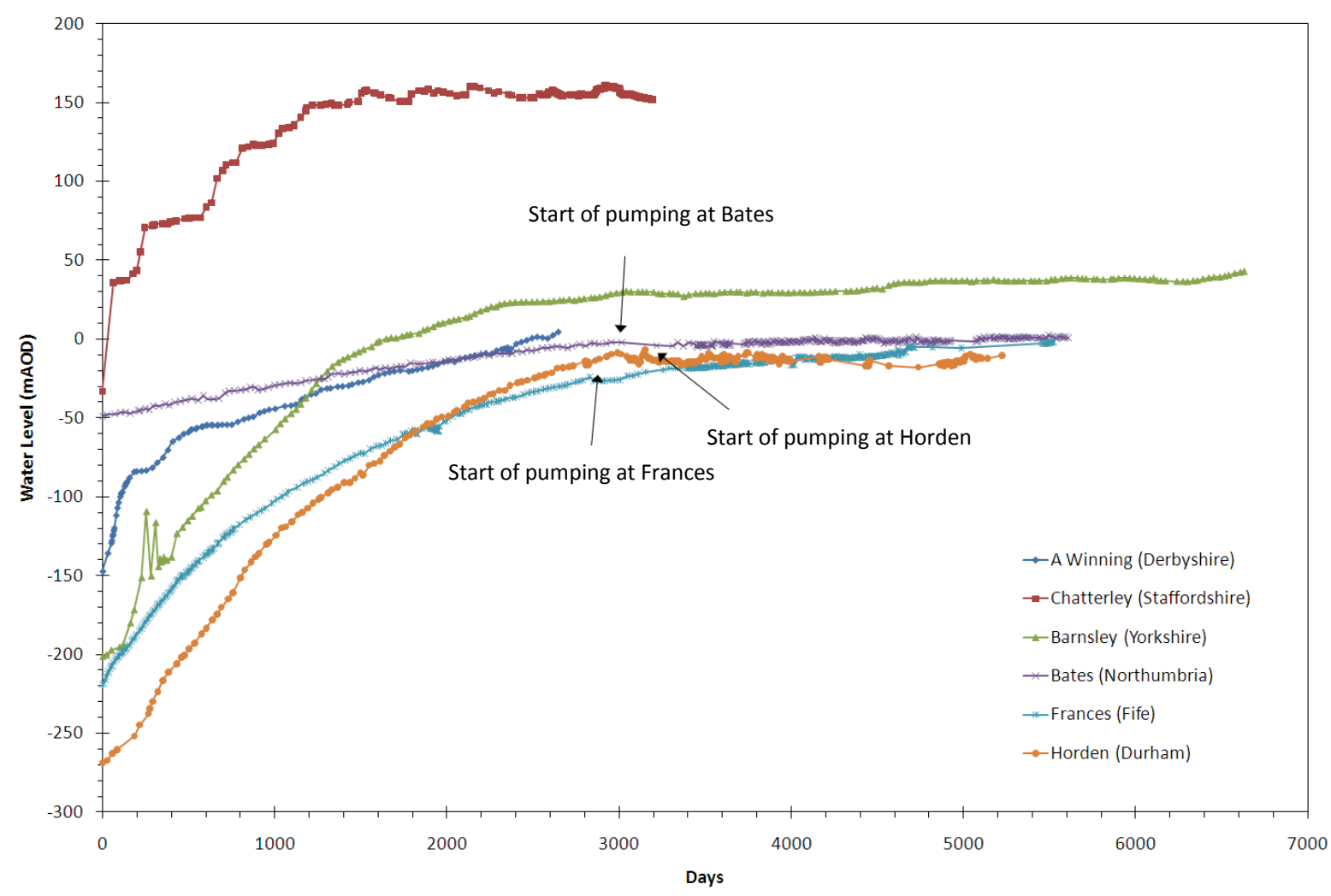

Figure 5 Selected UK recovery curves, normalised to days of start of monitoring the recovery

Date

Jun-94 Jun-95 Jun-96 Jun-97 Jun-98 Jun-99 Jun-00 Jun-01 Jun-02 Jun-03 Jun-04 Jun-05 Jun-06 Jun-07 Jun-08 Jun-09 Jun-10

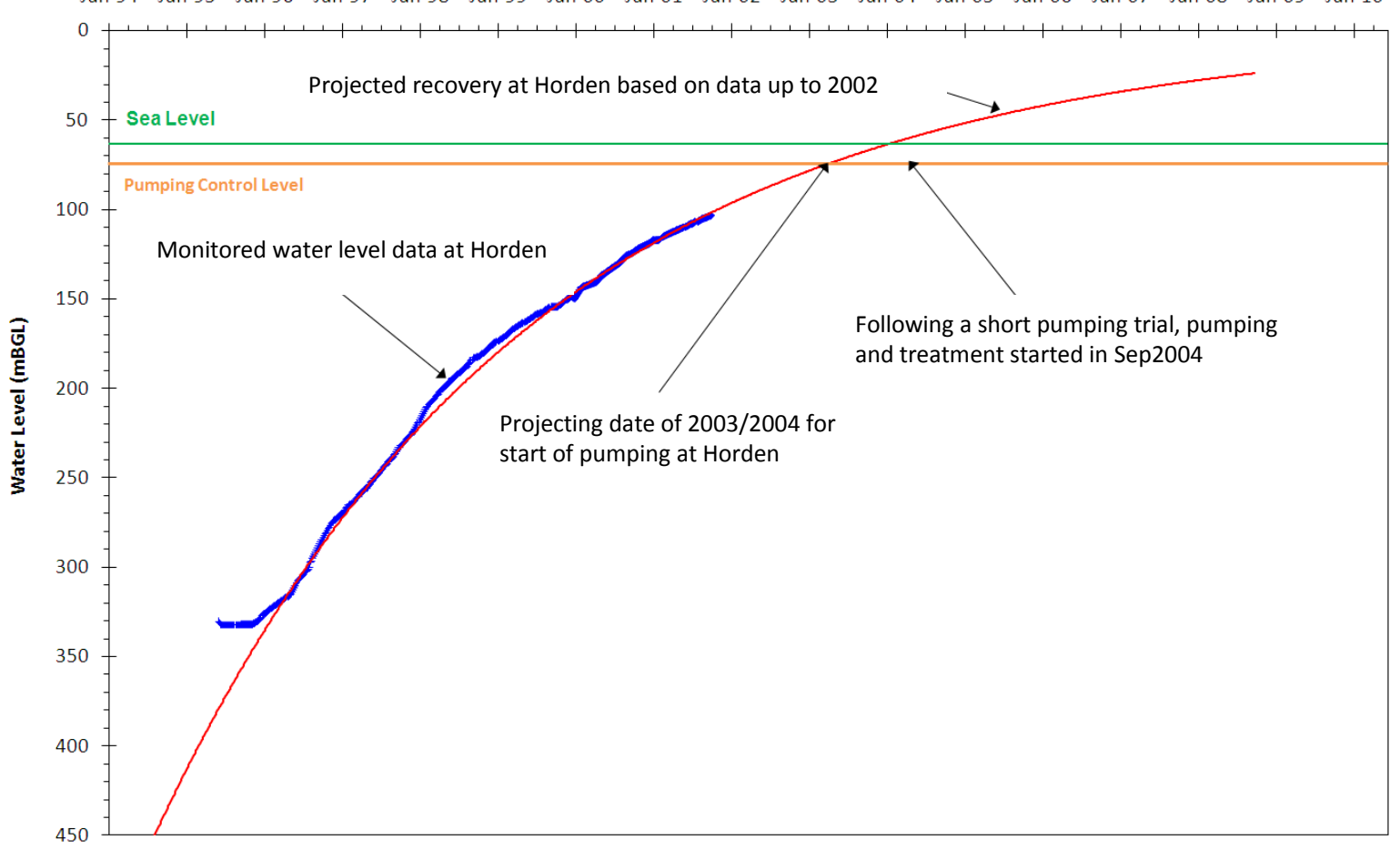

Figure 6 Rising mine water at Horden and the projected recovery 


\subsection{Predicting mine water chemistry}

When proposing remedial schemes for coal mine waters, knowing the anticipated chemistry, particularly iron concentration, is of principal concern. Often, however, historical chemistry data are limited or nonexistent, which makes the design and planning phase problematic. Where there are few no data, attempts can be made to predict the possible iron concentrations; this is typically easier for surface mines compared with underground mines (Younger, 2000). In underground coal mines, a number of both physical and chemical factors can contribute to the production of iron (Younger, 2000), which makes the chemical composition far more difficult to predict. Instead of implementing modelling techniques, the Coal Authority uses a different approach to aid with the assessment and the determination of the possible mine water chemistry, including the following:

- Discrete sampling of shafts: Samples of mine water are taken at various intervals down a mine shaft, preceded by a conductivity-temperature survey of the shaft to identify any 'step' changes in mine water chemistry. Prior to undertaking the survey, the inset levels in the shaft and other such factors are identified to indicate potential sample points. Often, the shaft column water can be stratified (Nuttall and Younger, 2004), thus it is important before pumping commences to adequately sample the entire shaft column and not solely the top of the water column. One such example of this is where bailed samples were taken from a borehole in South Derbyshire, which showed iron concentrations of about $40 \mathrm{mg} / \mathrm{L}$ and relatively low salinity (100 mg/L chloride). However, when the pumping test commenced, it was anticipated that the salinity might increase, and this was confirmed when the chloride concentrations increased to approximately $6,000 \mathrm{mg} / \mathrm{L}$ (Bailey et al., 2011).

- Old records: The Coal Authority reviews archive data, where available, particularly records of chemistry data, including pumped mine water, shaft inflow water and water encountered within the mine workings. These records can be used to provide a guide to future chemistry, while giving an estimate of the 'worst-case' scenarios.

- Pumping test: Throughout the UK, the Authority has undertaken a number of pumping tests to define the mine water chemistry of the water and assess abstraction rates and determine the effectiveness of controlling the mine water (Bailey et al., 2011). However, it should be noted that in some circumstances the actual pumped mine water can change temporally at the same location or can change when water is pumped through from different sections of mine workings. At Summersales in Lancashire, a pumping test was undertaken in 2007 that suggested an iron concentration of approximately $50 \mathrm{mg} / \mathrm{L}$. In 2009, a new pumping borehole was drilled, and a pumping test was undertaken, but the iron concentrations for this test were approximately 20-30 mg/L. At Frances shaft in Fife, Scotland, the iron concentrations are highly variable and have changed over time. Initial shaft sampling (Nuttall and Younger, 2004) indicated iron concentrations of $>500 \mathrm{mg} / \mathrm{L}$. This was confirmed by a pumping test in 2003 , in which the initial concentrations of $30-40 \mathrm{mg} / \mathrm{L}$ rapidly rose to over $600 \mathrm{mg} / \mathrm{L}$ of iron. This has been succeeded by a number of years of steady iron concentration of 30-40 mg/L. However, in more recent years the Authority has observed 'tidal' responses in mine water chemistry, with iron concentrations varying between 30 and about $300 \mathrm{mg} / \mathrm{L}$.

\section{$4 \quad$ Specific risks from rising mine water}

When water floods abandoned mine workings, a number of risks and events can develop, some of which occur during the period of mine water rebound, whereas others arise after rebound has taken place. The following are examples of some of these risks and events that the Coal Authority has managed in coalfields affected by rising mine waters post-closure. 


\subsection{Rising mine water resulting in release of mine gas}

The close relationship between coal mine gas and gas emissions to surface, in particular in response to barometric pressure changes (Carter and Durst, 1956), have long been known and are well documented. The affects of rising mine water has also been previously described (Burrell and Friel, 1996; Burrell and Whitworth, 2000), with models and calculations used to estimate mine gas (methane) reserves for coalfields based on rising mine water models (WYG, 2005; WSP, 2011). This section highlights some of the key findings from these previous studies and reports:

- Rising mine water on mine gas emissions: Observations and measurements made by the Coal Authority indicate that initially mine gas emissions occur through mine entries (both void and filled) where there are connections to the deeper mine workings. With rising water levels, some of the connections and the previously dry workings reduce in size and can prevent mine gases venting to the atmosphere through these mine entries (Figure 7). However, in some instances mine gas remains present, which can pose a risk to surface properties, especially in areas around surface coal seam outcrops and shallow workings (Burrell and Whitworth, 2000). In these areas, the mine gas requires venting safely to prevent risks associated with mine gas at surface.

- Mine gas emission through surrounding strata: In areas where there are unsaturated, porous strata (i.e., sandstone) that are connected to the mine workings, examples are known of mine gas migrating from the old workings to the surface via the bedrock geology. Burrell and Whitworth (2000) describe two such scenarios, both of which occurred in the Yorkshire Coalfield, where gasfilled workings are situated below unsaturated sandstones that crop out at surface. One example of this scenario happened around Kimberworth (near Rotherham, UK), where mine gas reached the surface in a built-up domestic area, which required number of boreholes to be sunk in order to safely vent the mine gas. Similar risks can also be found in other porous strata, such as opencast backfill.

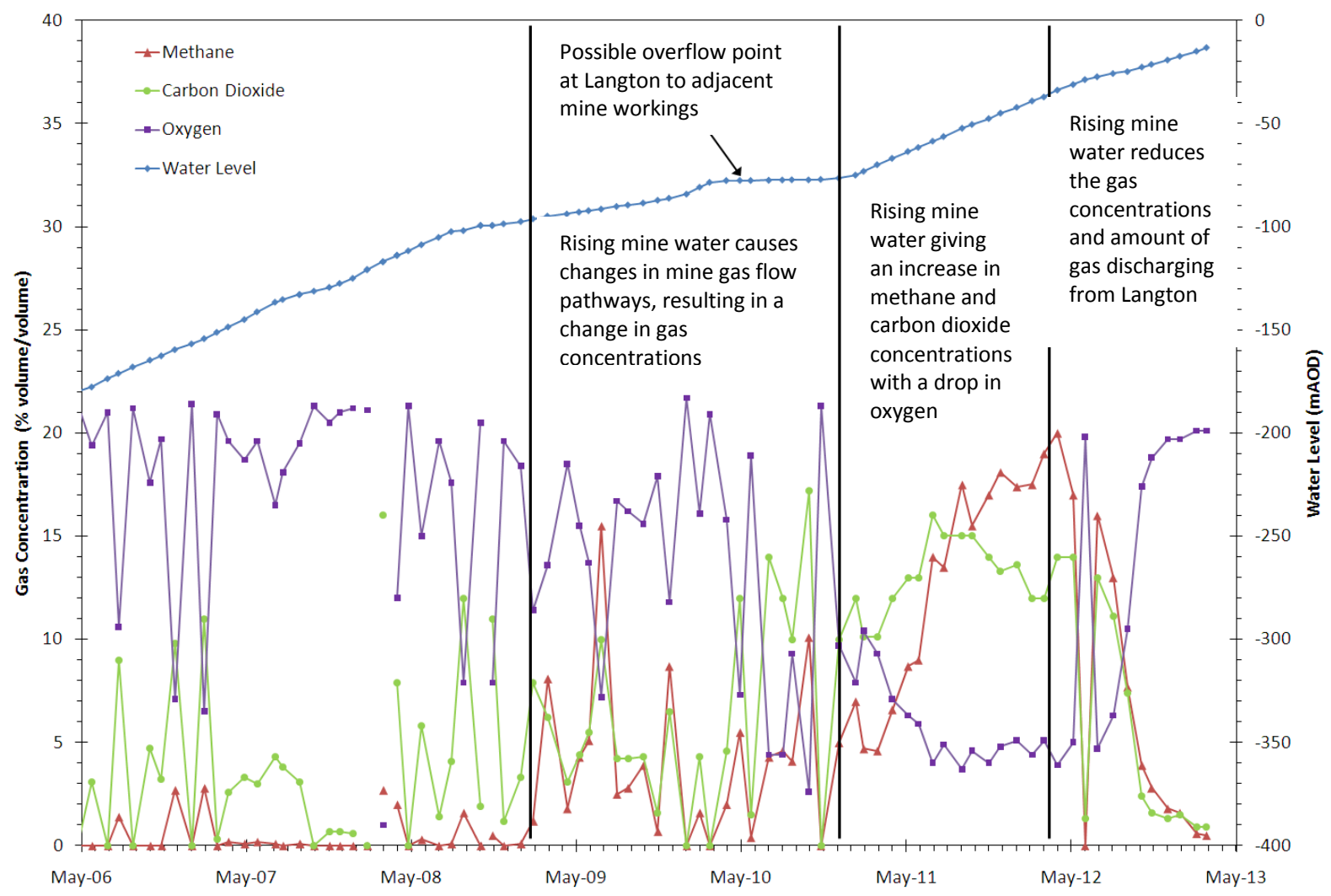

Figure 7 Rising mine water against measured gas concentrations at Langton, Derbyshire since 2006 


\subsection{Failure of underground dams and blockages}

It is common in UK coal mining blocks for collieries to be linked via underground connections; these connections vary and include multiple roadways, single roadways, boreholes and shafts in addition to water permeating through strata. Occasionally, when two mines are linked underground, dams are constructed to prevent water migration from one colliery to another. Such dams vary in nature, depending on their purpose - either to retain a large head of water or to simply impede water from flowing between mines. Apart from these purpose-built structures, other such restrictions can occur as a result of collapsed workings causing a blockage. When rising mine water causes a buildup of pressure on one side of a dam or blockage, and when these restrictions are not sufficiently substantial to hold back a large head of water, the obstructions are at risk of failure. This allows water to flow into a dry area of mine workings, which in some circumstances can enter areas that have a buildup of mine gas and/or can suddenly change mine gas pathways.

Figure 8 shows one such instance of a blockage failing (or in part giving way) at Oxcroft in Derbyshire, resulting in the water level dropping over time. At the time of this drop in water level, mine gas concentrations at Blacks Shaft (5.5 km to the north-northwest) changed from having 'atmospheric' values to raised concentrations of methane and carbon dioxide, with a corresponding reduction in oxygen concentrations. Aside from these unplanned events, there can be certain circumstances where raising water levels to deliberately cause a dam failure can be advantageous. At Sherburn Hill, County Durham, pumping was deliberately ceased in 1998 to allow water levels to rise and build up pressure against a hydrostatic dam, resulting in the dam failing. This resulted in the isolated area of Sherburn Hill synchronising with the rest of the mining block (Whitworth, 2002a) and removed the requirement for pumping at Sherburn Hill.

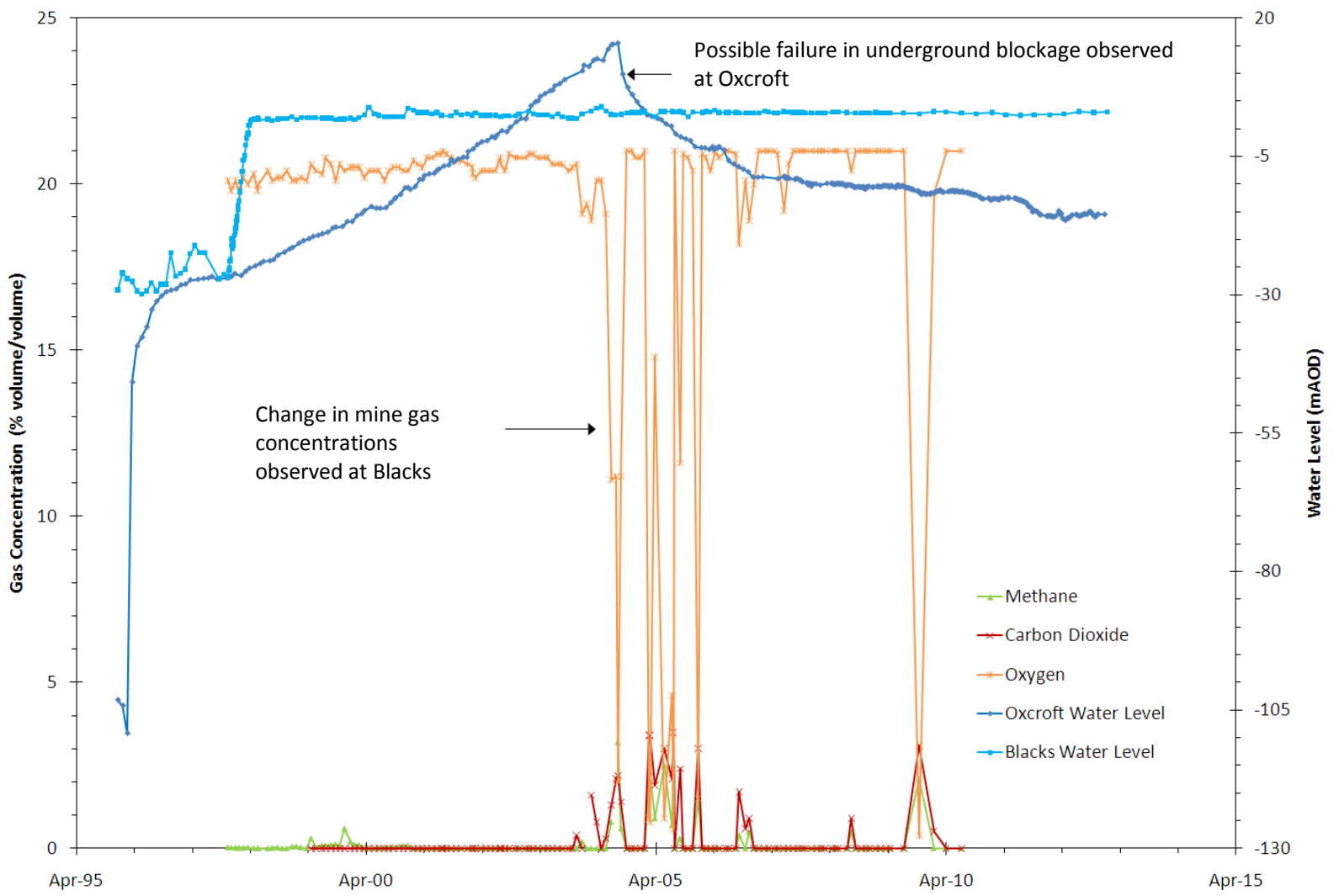

Figure 8 Water levels observed at Blacks Shaft and Oxcroft Shaft, Derbyshire, plotted against gas concentrations measured at Blacks Shaft 


\subsection{Aquifer pollution and groundwater rebound}

Within the UK, a number of the coalfields are concealed or in part concealed by overlying strata, typically of Permo-Triassic age. These strata often form important groundwater sources for both industrial and potable water supply. During mining operations, there is a risk of pollution to groundwaters originating from the presence of leachates from spoil mounds that may infiltrate the ground and contaminate aquifers, although modern spoil mounds should be designed to prevent this occurring. Where the geology and topography of the coal mining areas could allow for a head of water to be greater than the aquifer water level, there is a risk of 'leakage' from the mine workings into the aquifer. Elevated concentrations of chloride and sulphate are the principal contaminants. Below are examples of two aquifers that are being affected by rising mine waters, in one of which were pumping is being utilised to prevent pollution. In both cases, there are specific pathways and connections for the mine water to penetrate the aquifer:

- South of Butterknowle Fault: This area, shown in Figure 9, is located in the southern extent of the Durham Coalfield. Following cessation of mining and associated pumping in the 1970s, the mine water levels started to rise, and now the piezometric head in the mine workings is greater than that in the Permian aquifer (Waterchem, 2007). Due to some leakage from the aquifer into the mine workings, combined with the rising mine water, there has also been a rise in the overlying groundwater (Waterchem, 2007). Since about 1980, sulphate concentrations in the aquifer above the current EQS values of $250 \mathrm{mg} / \mathrm{L}$ have been measured (after WYG, 2007). Modelling of the sulphate concentrations in the Permian aquifer show an initial plume that is moving, suggesting an initial injection of polluted mine water, and a larger growing plume, suggesting a constant supply of contaminated mine water (WYG, 2007). The Coal Authority, in conjunction with the Environment Agency and the local drinking water supplier, is currently assessing if these plumes are likely to impact the drinking water supply, and what measures could be taken to address this situation.

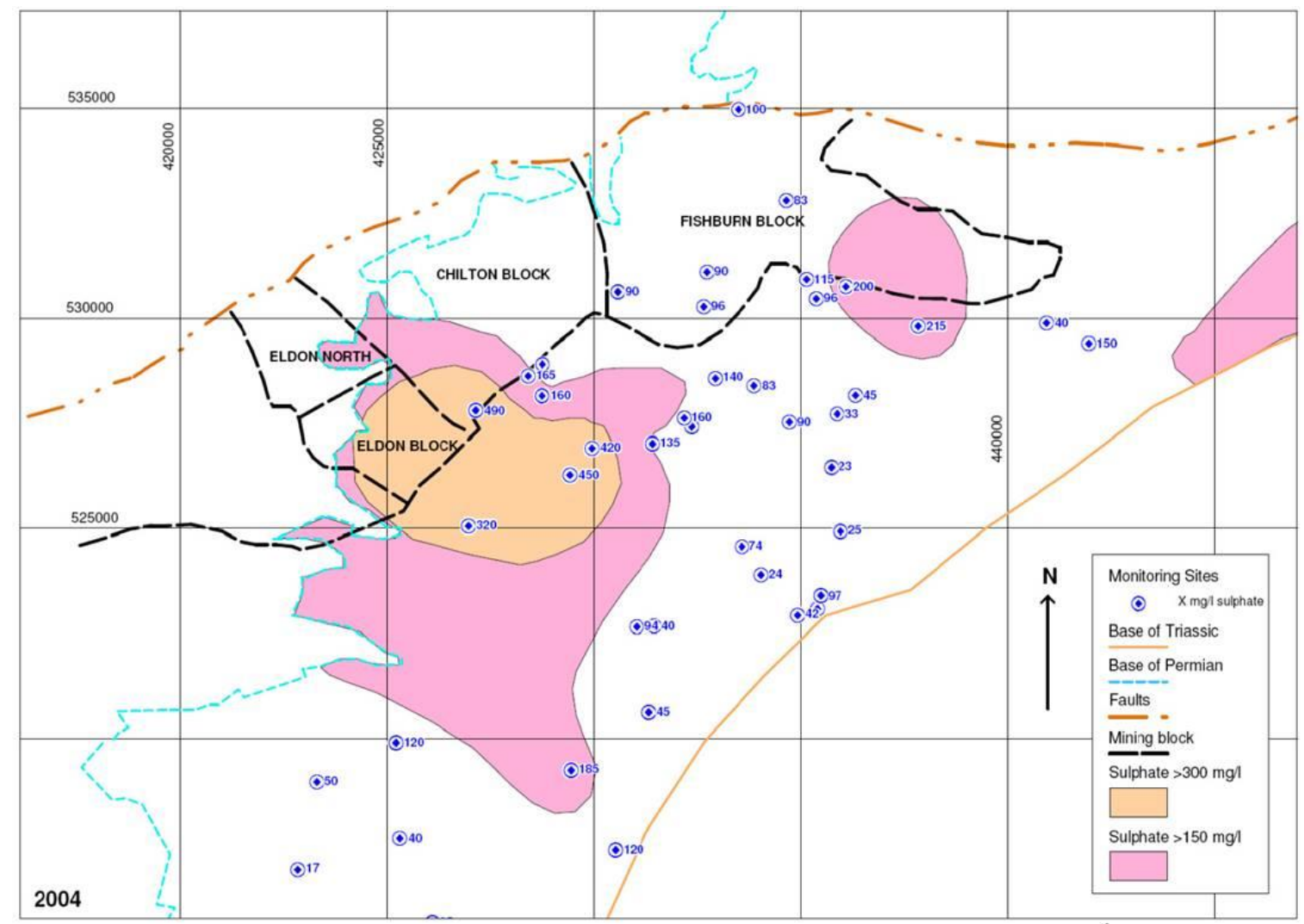

Figure 9 Plan showing elevated sulphate concentrations 'plume' c. 2004, in the Permian Aquifer in County Durham, UK (from WYG, 2007) 
- Horden area: This mining block is located along the coast of County Durham. At some collieries in the area, adits are present that go from the shafts into the aquifer, thereby creating specific pathways that could result in aquifer pollution. The Coal Authority monitored the mine water situation in the mining block, where mining ceased in the 1990s, and projected the probable recovery curve (see Figure 6) to determine when pumping should commence. In 2004, and following a short-term pumping test in 2003, the Coal Authority began abstracting and treating the water at Horden. Initially, the treatment at Horden was via an active chemical plant.

Subsequently, a scheme was built at Dawdon, due to the risks associated with the collapse / blockage of a single roadway connection. The active plant at Horden has since been demolished and replaced by a passive scheme of settlement ponds and aerobic wetlands to remove the iron, prior to discharging water to the North Sea. The pumping data from Horden and Dawdon show marginally hyper-saline water with chloride concentrations around $20,000 \mathrm{mg} / \mathrm{L}$; a small flow of approximately only $<5 \mathrm{~L} / \mathrm{s}$ (Waterchem, 2007) would be all that was required to contaminate the aquifer and raise the chloride concentrations above the EQS values of $250 \mathrm{mg} / \mathrm{L}$ for drinking water.

\subsection{Inadequate monitoring}

Although the Coal Authority monitors the majority of the principal coalfields in the UK, some of which are either currently rebounding or have recently recovered, there is still a risk of unknown and unforeseen events occurring, which can lead to other issues and problems arising (e.g., new gravity discharges) that could cause environmental damage. In the South Derbyshire Coalfield, a number of boreholes to vent and measure the mine gas concentrations were installed. No specific mine water level monitoring sites were present in this coalfield from its abandonment in 1990 until 2006 (Bailey et al., 2011), when one small pumping borehole was sunk in order to supply a nearby canal with water. In 2006, and after receiving the initial data from this pumping borehole, the Coal Authority commissioned another borehole to assess and validate the water levels. The monitoring data showed the water levels were rising and approaching the surface, with a risk of outbreak identified for only a few years later. Unfortunately, the situation was changing so rapidly that there was insufficient time to plan, design and build any remedial measures (i.e., pumping) to prevent any discharges from surfacing.

In the winter of 2007/2008, a small discharge $(<1 \mathrm{~L} / \mathrm{s})$ was observed around Cadley Hill. Additional monitoring boreholes were sunk and former gas boreholes utilised for water monitoring. To date there are nine mine water level monitoring boreholes throughout the coalfield. In 2009, a pumping test was undertaken to ascertain the potential mine water chemistry, abstraction rates and degree of control across the coalfield (Bailey et al., 2011). Since the pumping test ceased in 2009, the mine water levels continued to recover in the coalfield, and a second discharge (initial flow $<5 \mathrm{~L} / \mathrm{s}$ ) occurred at Saltersford, $7.5 \mathrm{~km}$ southeast of Cadley Hill (Moorhouse et al., 2013). Currently the Coal Authority is monitoring and assessing these discharges and any possible impacts. A small-scale treatment trial commenced at Saltersford in 2011 (Moorhouse et al., 2013) to assess the effectiveness of a Scoofi in removing iron from the mine water.

\subsection{Blowout from mine entries}

Around various parts of the UK there are a number of known gravity discharges, typically from old drainage adits, which have a history of blowout that manifests as a sudden release of a large volume of mine water over a short period of time. Usually these events are relatively short-lived (a few hours or days), and their impacts on receiving watercourses generally discolour and stain the receiving water for a limited number of days. The length impacted can be relatively extensive; a blowout at Old Meadows in 2008 impacted approximately $15 \mathrm{~km}$ of the River Irwell, and a blowout at Jackson Bridge (Hazlehead) adit, impacted approximately $10 \mathrm{~km}$ of watercourse, including the receiving stream and the River Holme.

Other such blowouts can occur due to adit mouths becoming blocked off or even covered by spoil tips and other surface works. One such example was at Taylor and Tunnel Pit, when ochreous mine water was seen emerging from some spoil material near to the mouth of the tunnel (Whitworth, 2002b). This required a 
borehole to be drilled into the tunnel to relieve the buildup of the $5 \mathrm{~m}$ head of water. $\mathrm{In}$ such cases, the potential exists for water to affect the stability of overlying structures such as spoil mounds and embankments, which could lead to catastrophic failure. On occasions there are blowout events from adits that appeared to be free-flowing water (although flow rates may have been reduced), from which material (i.e., rocks and boulders) were removed, resulting in the blowout.

The Sheephouse Wood adit, Yorkshire, is located less than $50 \mathrm{~m}$ above the main A616 road, and in 2002 a blowout occurred (Whitworth, 2002b) that resulted in material washing down across the road (Figure 10), causing significant damage to the highway and closing this vital transport link. Emergency works were undertaken to resurface the road, allowing it to be reopened, while at the same time installing measures to prevent such an event from occurring again.

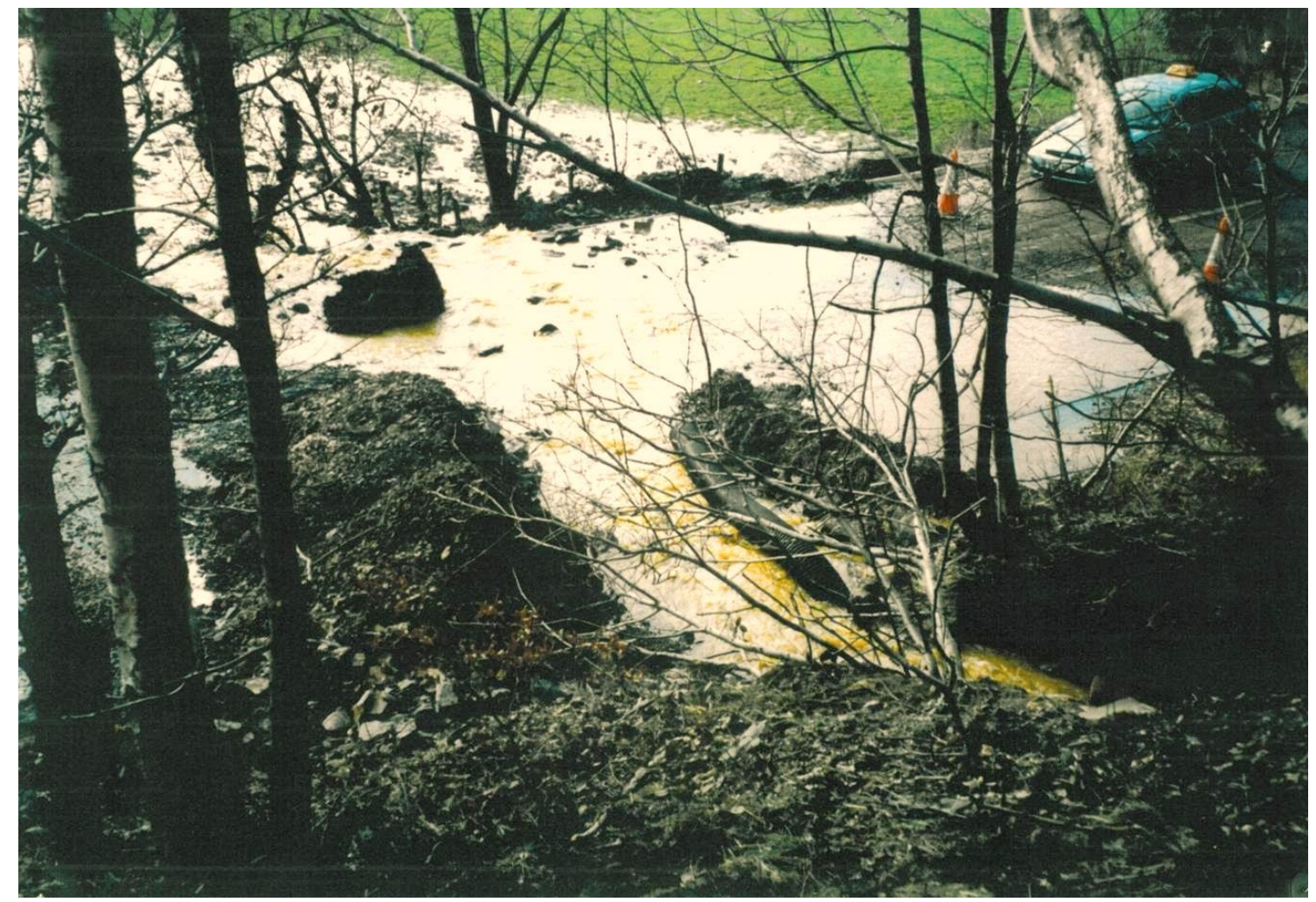

Figure 10 Blowout from Sheephouse Wood Adit, February 2002, which removed part of an embankment and damaged the A616 main road (Coal Authority ( $)$ February 2002)

\subsection{Surface developments affecting mine workings}

In addition to the risks described above, there are other hazards that can be mine water related. One such risk is related to surface works, including drilling and grouting operations affecting the coal workings, drainage systems and mine water or mine gas flow paths. In order to protect estate and property interests (i.e., the underground mine workings), the Coal Authority requires prospective developers to assess the impact of their proposal on the mining regime. Permission to intersect or undertake works is given, provided that a Coal Mining Risk Assessment has been undertaken and the risks properly addressed by the developer. Examples of problems resulting from unauthorised work are difficult to distinguish. However, there have been instances where grouting of mine water flow paths has resulted in new surface mine water discharges.

The other primary concern from such operations affecting mine workings, especially if the workings are unsaturated and situated close to domestic or industrial property, relate to the method of drilling and flushing of arisings. The Coal Authority has therefore, in association with other interested parties, published 
guidance notes for drilling through coal measures and managing the risk of mine gas (Coal Authority, 2012), particularly the risk associated with spontaneous combustion and carbon monoxide.

\section{Conclusions, changes made throughout time and the way forward}

Since 1994 the Coal Authority has undertaken a number of changes to the management of mine water, monitoring and associated operational needs. These changes include increasing its knowledge of mine water throughout coalfields via a wide network of monitoring sites. By monitoring and assessing water levels, mine gas, rainfall, barometric pressure, mine water chemistry and treatment scheme chemistry, the Authority has vastly improved its knowledge and understanding of how mine water recovers and the impact of this on the mining block. More recently, reviews of mine water treatment scheme data has led to a much better understanding of operational efficiency, maintenance issues and assists in improving the methodology to develop improved sizing criteria for new treatment schemes.

Going forward, the Authority in conjunction with other partners has been looking for a better understanding of the mine water and its potential use as a renewable energy source (mini-hydro and ground source heat), in addition to ways to improve and manage their ochre waste by reuse. Within its forward programme of remedial schemes, a number of challenges relate to cost-benefits and in particular land availability and size of treatment schemes. Thus, to further this work and progress, a number of recent trials for iron removal have been utilised, including use of high-surface media with low footprint areas (Moorhouse et al., 2013; Wyatt et al., 2013). In conjunction with these trials, the Authority has moved more into research and development, developing a research and development programme, to better enhance its existing and future mine water treatment schemes.

\section{References}

Adams, R. and Younger, P.L. (2001) A strategy for modelling ground water rebound in abandoned deep mine systems, Ground Water, Vol. 39, pp. 249-261.

Bailey, M., Watson, I., Wyatt, L. and Davies, T. (2011) Applications of pumping tests in the development of mine water management strategies and remediation schemes, in Mine Water - Managing the Challenges, R.T. Rüde, A. Freund and C. Wolkersdorfer (eds), Aachen, Germany, pp. 97-100.

Burrell, R. and Friel, S. (1996) The effect of mine closure on surface gas emissions, in Proceedings IBC UK Conference on the Environmental Management of Mining Operations, 23-24 September, London, 15 p.

Burrell, R. and Whitworth, K. (2000) The influence of minewater recovery on surface gas and water discharges in the Yorkshire Coalfield, in Proceedings 7th International Mine Water Association Congress, Ustron, pp. 81-90.

Carter, W.H.N. and Durst, C.S. (1956) The influence of barometric changes on the emission of firedamp, Transactions of Mining Engineering, Vol. 115, pp. 3-29.

Coal Authority (2012) Guidance on managing risks of hazardous gases when drilling or piling near coal, Mansfield, UK, $59 \mathrm{p}$.

Coal Industry Act (1994) An Act for the establishment and functions of a body to be known as the Coal Authority; to provide for the restructuring of the coal industry for transfers of property, rights and liabilities of the British Coal Corporation and its wholly-owned subsidiaries to their persons for the dissolution of that Corporation; to abolish the Domestic Coal Consumers' Council; to make provision for the licensing of coal-mining operations and provision otherwise in relation to the carrying on of such operations; to amend the Coal Mining Subsidence Act 1991 and the Opencast Coal Act 1958; and for connected purposes, House of Commons.

Moorhouse, A.M.L., Wyatt, L.M., Watson, I.A. and Hill, S. (2013) A high surface media treatment trial of a circum neutral, net alkaline coal mine discharge in the South Derbbyshire Coalfield (UK) using hydrous ferric oxide, prepared for International Mine Water Association Conference, Colorado, 2013.

Nuttall, C.A. and Younger, P.L. (2004) Hydrochemical stratification in flooded underground mines an overlook pitfall, Journal of Contaminant Hydrology, Vol. 69, pp. 101-114.

Waterchem (2007) Optimization of Mine Water Discharge by Monitoring and Modelling of Geochemical Processes and Development of Measures to Protect Aquifer and Active Mining Areas from Mine Water Contamination, Technical Report No 7, Research Programme of the Research Fund for Coal and Steel Coal RTD, Waterchem project RFC-CR-03006, 156 p.

Whitworth, K.R. (2002a) The monitoring and modelling of mine water recovery in the UK coalfields, in Mine Water Hydrogeology and Geochemistry, P.L. Younger and N.S. Robins (eds), Geological Society, Special Publication 198, London, pp. 61-73.

Whitworth, K.R. (2002b) Day eyes, level rooms and the importance of sough things for mine water drainage, in Mine Water Treatment: A Decade of Progress, C.A. Nuttall (ed), Proceedings of a Conference in Newcastle upon Tyne, UK. 
WSP (2011) Update of Estimated Methane Emissions from UK Abandoned Coal Mine, prepared for Department of Energy and Climate Change, $37 \mathrm{p}$.

Wyatt, L.M., Watson, I. and Sawyer, T. (2011) 15 years of mine water analysis and developments in monitoring of abandoned coal mines in the United Kingdom, in Mine Water-Managing the Challenges, R.T. Rüde, A. Freund and C. Wolkersdorfer (eds), Aachen, Germany, pp. 645-649.

Wyatt, L.M., Moorhouse, A.M.L. and Watson, I.A. (2013) Full scale pilot test of a novel technology to remediate alkaline coal mine water using high surface media at Acomb Mine Water Treatment Scheme, UK, prepared for International Mine Water Association Conference, Colorado, 2013.

WYG (2005) Development of a Methodology for Estimating Methane Emissions from Abandoned Coal Mine in the UK, prepared for Department for Environment, Food and Rural Affairs, 118 p.

WYG (2007) Analysis of Mine Water Plume Chemistry Data for the South of Butterknowle Fault Area, prepared for the Coal Authority, $56 \mathrm{p}$.

Younger, P.L. (2000) Predicting temporal changes in total iron concentrations in groundwaters flowing from abandoned deep mines: a first approximation, Journal of Contaminant Hydrology, Vol. 44, pp. 47-69.

Younger, P.L. and Adams, R. (1999) Predicting Mine Water Rebound, Environment Agency Research and Development Technical Report W179, $120 \mathrm{p}$. 